\title{
Plugging Back Into The Matrix
}

\section{The Intertextual Flow of Corporate Media Commodities}

Jennifer M. Proffitt

Florida State University

Djung Yune Tchoi

Matthew P. McAllister

Pennsylvania State University

This article argues that The Matrix franchise provided global Hollywood with a model for channeling revenue and fans through different multimedia revenue streams via linked commodity narratives. Building on previous theoretical concepts of the expansion of corporate media texts, the article discusses The Matrix as "commodified intertextual flow" where various consumable forms were marketed as narratively necessary purchases for Matrix fans. Ultimately, The Matrix as a narratively integrated brand expanded the marketing strategies for commodity-oriented media texts and undermined the original film's critique of consumer culture. The integration of DVD technologies, release strategies, and ancillary licensing constructed a narrative necessity and "community" of fans who may have felt compelled to buy into the complete multicommodity narrative.

Keywords: The Matrix; film marketing; flow; commodity intertext

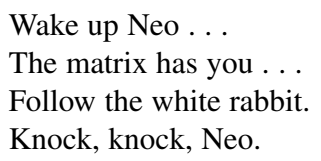

-From The Matrix

$\mathrm{I}^{\mathrm{n}}$ many ways, 1999's The Matrix, which eventually grossed more than $\$ 460$ million worldwide, was an odd Hollywood blockbuster from a major studio, in this case Warner Brothers Pictures. Larry and Andy Wachowski, the brothers who wrote and directed the film, were relatively unproven. Their previous movie, Bound, was a seemingly noncommercial noirish film with lesbian protagonists; USA Today labeled the two brothers as "anti-Hollywood" (Chetwynd, 1999, p. D5). The Matrix's "R" rating limited the potential teen audience normally cultivated for an action movie. Its plot was viewed as too complicated for audiences and more esoteric than the tried-and-true action films Warner usually produces (Natale, 1999). One analyst labeled The Matrix as the cyberpunk "antithesis" to its more traditional 
sci-fi rival that summer, Star Wars: The Phantom Menace (Harrison, 1999, p. 1). Shot in Australia to cut costs, The Matrix had a relatively modest $\$ 63$ million budget (Natale, 1999) compared to the $\$ 115$ million budget for Star Wars: The Phantom Menace. Given these factors, Time Warner's subsidiary, Warner Brothers Pictures, did not expect The Matrix to reap the cult following and profitable status it secured. Even 2 weeks after the unexpectedly lucrative release, sequels had "only been briefly discussed" (Natale, 1999, p. 14).

However, this seemingly haphazard "anti-Hollywood" approach soon changed. With the success of the original film, plans for the sequels (actually one movie split into two parts) and their marketing campaign were launched into action. According to Joel Silver, producer of The Matrix trilogy, the Wachowski brothers envisioned the unfolding of the story of The Matrix to occur in multiple media, resulting in a "glorious experience" for fans (see interview in "Entering the Matrix: Making the Game" from the second disc of The Matrix Reloaded, 2003). The Matrix, a dark and critical film deemed a "cult classic," emerged as a commodified franchise with multiple revenue streams targeting fans worldwide.

Indeed, Hollywood blockbusters have become global motion picture events that exploit multiple revenue streams. The Matrix franchise demonstrates, and even further expands, the continuing and vast economic power of the major studios of Hollywood and how the Hollywood blockbuster constructs a global film event throughout multimediated and coordinated production, distribution, and exhibition. The aim of this article is to explore a specific textual event, The Matrix, its sequels, and subsidiary outlets, within the context of global Hollywood in the information age. This article will argue that The Matrix franchise provided a model for channeling revenue, and therefore fans, through different multimedia revenue streams via linked narratives that expand the nature of the corporately created, commodityoriented media text. This article will first present a framework for analyzing a converging, globally expansive Hollywood and then examine the strategies of flow and synergy used by Time Warner and its partners to move Matrix fans to multiple media platforms and to create and sustain a profitable global textual event.

\section{The Changing Nature of the Corporate Mediated Text}

Late 20th-century corporate-controlled media had moved from earlier models of separate media industries using discrete funding systems to larger scale integrated cultural and media systems. As a rule of thumb and of course with significant exceptions, the different media industries in the early and middle half of the 1900s functioned autonomously, with film, broadcast, recorded music, magazines, and so on having their own revenue streams, trade organizations, media technologies, dominant companies, and regulatory environments. Although certainly international revenue streams were lucrative, for the most part, these media industries focused on domestic markets (Miller, Govil, McMurria, Maxwell, \& Wang, 2005). 
Several factors coalesced to integrate and complicate the structure of media industries. Technology such as cable television, VCRs, and later digital media created new outlets for media content; global markets also encouraged corporate growth, with Hollywood often generating more revenue from the international than domestic box office for a given blockbuster film (Wasko, 2003). Notions of complementary ownership strategies ("synergy") and business-friendly regulatory environments encouraged the rise of multimedia empires, where one company can become a major player in several media industries; product advertisers, looking for ways to break through the "clutter" and prevent ad avoidance by audiences, see these global, multimedia conglomerates as natural tie-in partners (McChesney, 2004). Certainly, the structure of and social relations in this industrial context are complex and often contradictory (Hesmondhalgh, 2002), but nevertheless, examples of coordinated cultural power exerted by the cultural industries are quite visible.

Many scholars have argued that in this multimediated global-corporate environment, the nature of the "text" is problematized and continually changing (Bird, 2003; Brooker, 2001; Couldry, 2000). One of the earliest critics of this change was Meehan (1991) in her analysis of Warner's 1989 film Batman. She argues that a modern character-brand like Batman should be conceptualized as a "commercial intertext" in which synergistic corporate owners move the brand across controlled film, music, videogame, print, and toy outlets. To understand the text and intertext of a cultural product, "an economic analysis of corporate structure, market structures, and interpenetrating industries" is necessary (p. 49). That is, it is necessary to understand the new economic structures that produce intertexts, including the practices and strategies used by media conglomerates to exploit successful cultural products across outlets.

Batman, in fact, was originally a comic book series "that was already earning revenues" for the then-named Warner Communications, Inc., having earlier acquired DC Comics and its superheroed characters (Meehan, 1991, p. 52). Thus, the film had a preconstituted audience. Prince's "Batdance" song played on radio stations that targeted African American audiences, and the accompanying video that was frequently shown on MTV had a crossover effect, cultivating a larger fan base for the film, including females, people of color, and middle-class White youths, the primary target audience of MTV (Meehan, 1991).

However, Meehan's original conceptualization of the commodity intertext-a characteristic of synergy strategies throughout the 1990s-emphasized the repetition of brand appearance rather than a continuation of the brand's narrative arc. For the most part, the Batman soundtrack, VHS release, amusement-park ride, or t-shirt did not further develop the plot or back story of Batman but rather was a way to duplicate the brand in different locations or outlets. Outlets that potentially could expand the narrative of Batman, such as the novelization or comic-book adaptation of the film, were relatively marginal licensing segments.

Although media corporations still rely on traditional licensing revenues, digital and globally distributed technologies such as the Internet, DVDs, video game consoles, 
and mobile media such as cell phones greatly expand marketing possibilities and thus potential manifestations of the corporate text. Along these lines, Couldry (2000) suggested that researchers examine "textual environments" rather than a single text per se. The textual environment consists of a number of flows, which include (a) "the material structures of textual production," (b) "the material structures of distributing texts," and (c) "the process which tend to order how we read, what connections we make between texts, what texts we screen out, and so on" (p. 81). These tasks require studying texts not as static "objects" but as changing "textual processes" (p. 86). Couldry argued that "complex textual environments, texts which attract a great deal of close reading are not simply 'there': they emerge as part of a textual event which needs to be studied" (p. 86).

Textual events are therefore dynamic, created by the media industry to be moved through multimedia outlets. A key contribution here is the use of "flow" as a metaphor and the associations with movement and sequence that this metaphor implies. As originally conceptualized by Williams (1974), flow described how broadcast networks keep audiences throughout the day (and night) via self-promotion of its own programming. In more recent contexts, flow is not just a television phenomenon but also relates to the movement of audiences to different media via interlinked narratives. The goal is to move fans from the original "text" to other texts such as narratively connected video games, Web sites, and DVD releases that do not just duplicate the original text but "advance" it. Brooker (2001) noted that current television programming exhibits the concept of "overflow"-that is, the flow of audiences from a program, such as Dawson's Creek, to multiple media platforms, particularly the Internet. He argues that the Dawson's Creek Web site offers narrative features not found while watching the television text, such as character diaries; thus, "the internet permits the illusion that the characters have ongoing lives between episodes, and pulls it off convincingly" (p. 461).

Such supplemental texts have a strong commodity orientation to them. Fuqua (2003) argues that the merchandising and licensing activities of The Powerpuff Girls tended to remove empowering — and potentially less marketing friendly_ideologies of the original animated text. Similarly, Brooker's interviews with U.S. Dawson's Creek fans found that there was a tendency for them to view "Dawson's Creek as a part of their everyday lives as consumers," especially because of cross-promotional activities with marketers which became part of the textual flow (p. 464).

Integrating the above work, what we see is a "commodity inter-textual flow," which is not just a duplication of the license but increasingly a necessary condition for loyal fans, if these fans desire to be "well rounded" in the narrative development of the brand. Thus, beyond Meehan's case study, it is not enough to just wear the Batman hat but also to be well versed in the character motivations as revealed in other Batman digital media.

It is in this context that The Matrix and, more importantly, the subsequent textual flows of the original movie were introduced. The remainder of this article discusses The Matrix as commodified intertextual flow where various consumable forms were 
marketed as narratively necessary purchases for Matrix fans. The section below discusses the integration of DVD technologies and release strategies to construct narrative necessity and a "community" of Matrix fans who may feel compelled to buy into (quite literally) the narrative. The sections that follow analyze this strategy with subsequent ancillary licensing and corporate tie-ins that further enhanced the narrative flow of the Matrix brands.

\section{The Matrix Movies: DVD Narrative Flow and Community-Building Release Strategies}

The Wachowski brothers brought an unconventional story development and storytelling orientation, at least for the film industry, to The Matrix. Their experiences as former writers for Marvel comics may have been an influence. Chetwynd (1999) reported that the Wachowski brothers had worked on the film for more than 5 years, completing " 14 screenplay drafts and, in an almost unheard-of move, supervis[ing] about a half-dozen artists who drew up storyboards (some 500 in all) of every scene to persuade Warner Bros.' top brass to make the film" (p. D5). In addition, Harrison (1999) noted that the brothers included "comic-book stories on the movie's Web site (http://www.whatisthematrix.com) that supplement the film by further delineating the world of the future" (p. 1). The emphasis on "backstory," especially given that the use of the Internet as a form of movie promotion was still relatively new, now can be seen as the first of many influential strategies for moving fans from one medium to another, tantalizing fans of the film to flock to the Web site for additional information about the frightening world of the future, and enticing Web-savvy fans to see the film.

The timing of The Matrix is also relevant as a transition from VHS to DVD formats for home sales and rentals, timing that allowed this franchise to eventually set the standard for home-video sales and marketing. A "no-frills" version of the first movie was released on VHS in September of 1999, a fairly conventional 6 months after the theatrical release. The accompanying DVD release, on the other hand, included a wide-screen version of the film, the film trailer, an HBO (also owned by Time Warner) documentary, "Making the Matrix," and "a music-only audio track with commentary by composer Don Davis"; furthermore, those consumers with computer access could access the DVD-ROM to "read the screenplay and follow the process by viewing each scene's storyboards, stills and final cuts" (King, 1999, p. 45). The DVDROM also included a "Do you know kung fu?" feature and "three original essays [that] offer a retrospective on comic-book-based films, the martial arts and sci-fi films" (p. 45). Industry trade journal Billboard later declared this release to be "a breakthrough DVD that for the first time showcased the format's versatility and DVDROM capabilities" (Fitzpatrick, 2001, p. 75). Unfortunately for some fans, and illustrating the emphasis on the "extratextual," the DVD had so many extras that it froze up their DVD players, and those using the DVD-ROM experienced difficulties as well (Fitzpatrick, 1999). And 9 weeks later, "in the shortest repricing window in recent 
memory," the VHS collector's edition of the film was released, which included 26 min of additional footage at a cost of $\$ 14.95$ (Prange, 1999, p. 37). A "Limited Collector's Edition" DVD, with a nicer slipcase and the CD soundtrack, was also released in November 1999.

In addition to the extras that the DVD offered, the promotion of the DVD also introduced narrative necessities. Warner, "push[ing] the envelope of DVD interactivity," played host to "a DVD screening and live Web chat with the creators of The Matrix" in November 1999 (Sporich, 1999, p. 10). Sporich (1999) noted that what made the Matrix event different from "other live chats with filmmakers on the Internet" was Warner's synchronization of the "playing of the DVD discs running on thousands of consumer computers around the world during the live chat" (p. 10) so that viewers could watch the film together. As the film played, viewers could ask the Wachowski brothers questions via a live chat box scrolling on the same screen. Jim Wuthrich, Warner's vice president of Internet marketing, was quoted as stating, "We expect this to be the largest single screening in history. But more importantly, this is an extension of the DVD experience" (Sporich, 1999, p. 10). Thus, to be a part of the Matrix DVD "communal" experience, fans would need to not only have computer access but also purchase the DVD format. Indeed, by November 2003, 30 million copies of the DVD version of the movie were sold, a feat that was in large part the reason that Time Warner garnered some 30\% of the DVD market in 1999 (Alexander, 2000; Holson, 2003). It was the first DVD to sell more than 1 million units and eventually sold more than 3 million (Fitzpatrick, 2001). To be sure, the original The Matrix had an enormous global fan base, as 1,100-plus Matrix fan sites had appeared on the Internet (Bowles, 2003a).

As noted, plans for the sequels were "only briefly discussed" early in the film's theatrical release (Natale, 1999, p. 14). Producer Joel Silver stated, "The more success the movie has, the more willing [the Wachowski brothers will] be to write it down" (Corliss, 1999, p. T6). The first film was a success despite Warner's misgivings, raking in $\$ 73.3$ million in the first 2 weeks of its April 1999 theatrical release (McCourt, 1999). Indeed, the risk of producing the sequels was minimal, as The Matrix eventually yielded nearly $\$ 500$ million worldwide and a multitude of devoted fans.

In 2003, labeled the "Year of The Matrix," Time Warner launched an extraordinary marketing campaign targeting fans of 1999's The Matrix and potential new fans. The Matrix Reloaded, the first sequel, opened in May 2003 with both an animated series, Animatrix, and a video game, Enter the Matrix, released on the same date (both of these ancillary outlets are discussed in the next section). This marketing scheme may have struck hardcore fans as "selling out," but The Matrix Reloaded grossed \$281 million domestically and \$735 million globally within 6 months of its release (Bowles, 2003b). Combined, the original The Matrix and its first sequel took in more than $\$ 1.5$ billion in box office receipts; home video, video game, and soundtrack sales; and apparel (Bowles, 2003b). 
Fans were also expected to create a lengthy queue on November 5, 2003, with the premiere of The Matrix Revolutions, a second sequel filmed at the same time as Reloaded and released only 6 months subsequent. The release of the two sequels within months of each other was a strategy used to enhance "momentum and continuity" (Seiler, 2002, p. D7). In September 2003, Warner Brothers had announced the simultaneous global release of this third film of the trilogy. This unprecedented distribution scenario made The Matrix Revolutions available to global fans at 6 a.m. in Los Angeles, 9 a.m. in New York, 2 p.m. in London, 5 p.m. in Moscow, 11 p.m. in Tokyo, and at corresponding times in more than 50 countries (Warner Bros. Pictures, 2003). The simultaneous opening of The Matrix Revolutions, according to Warner Brothers, was motivated by the desire of the directors to give fans the chance to view the final film of the trilogy at the same time, just as the interactive 1999 DVD experience allowed fans to do. Dan Fellman, President of Warner Brothers' Domestic Distribution, said, "The zero hour simultaneous opening of The Matrix Revolutions once again positions the Matrix films as the cutting edge experience in motion pictures" (Warner Bros. Pictures, 2003). ${ }^{1}$

Although the cost of producing the sequels had increased considerably, from $\$ 63$ million for the inaugural film to nearly $\$ 175$ million for each sequel, the payoff for Time Warner and Village Roadshow, as Lippman (2003) noted, was expected to be "huge," in part because the Wachowski brothers' and Silver's percentage of revenue from the sequels was much lower than some of the deals made for other blockbuster films, for such revenues cut into the studios' profits. Furthermore, based on the 30 million-plus DVD and VHS sales of the first Matrix, sales for these versions were projected to be high for the second sequel, which would be released before the theatrical release of the third film. Additionally, TV rights, both domestic and global, were expected to bring in an additional \$100 million (Lippman, 2003).

The first sequel, The Matrix Reloaded, opened on 8,400-plus screens, with previews that began the night before in approximately 2,000 theaters (executives expected several theaters to screen the film around the clock) (Eller, 2003b). The second sequel, The Matrix Revolutions, opened on 10,013 screens (Holson, 2003). With such a fixation on the blockbuster and multiple sequels, it is difficult not to ask the question, what is not being produced? That is, as the number of screens that procures one film increases, the number of films that can be shown at any one time decreases. With the increase in production and marketing costs, Hollywood studios expect to make large profits on a few globally appealing blockbuster films. And, as Eller (2003b) reported, Warner wanted to "reap as many dollars as possible, as quickly as it can," for as Warner's distribution chief Dan Fellman stated, "Remember, we call it the movie business" (p. C1).

The case of Time Warner's Matrix trilogy demonstrates the multiple strategies Hollywood studios can and most likely will continue to use to encourage the flow of audiences to multiple media, concurrently maximizing their profits and minimize costs and risks. With $\$ 300$ million production costs and marketing costs expected to surpass $\$ 100$ million (Eller, 2003a), The Matrix sequels were expected to sell to global 
audiences through multiple revenue streams, including box office receipts, DVD sales, pay-per-view, and IMAX theater box office returns. However, revenue from the original films was only part of the Matrix's story as intertextual commodity flow. To insure audience flow to additional revenue sources, promotional videos, video games, and the Animatrix series were marketed as must-haves for Matrix fans, for to understand the complexity of the movie's Matrix, one needed to purchase additional media.

\section{Synergizing The Matrix: Achieving Flow Through Ancillary Narratives}

In 2001, as The Matrix sequels were in production, Warner released the Matrix Revisited, a 2.5-hr DVD/VHS that included material that did not appear on the first DVD version of the film. Tellingly, the Matrix Revisited did not include a print of the original film. As an "extras-only" DVD, it featured interviews, behind-the-scenes footage, and previews of the two sequels and an animated version. But one thing it was not was free. For $\$ 19.98$, one could purchase the Revisited DVD, and for an additional $\$ 20$, one could own a two-disc set that included the film. The reason for such a release, as explained by Silver, was purely promotion: that with 2.5 years between the original film and the sequels, "we want to make sure people don't forget us" (Nichols, 2001, p. E1). Though the DVD was marketed as "going behind the scenes of the sequel," most of the additional footage was filmed at the same time the original film was being produced (p. E1). The DVD, marketed as a must-have sneak preview, did help to pique fan interest in the sequels. It thus served as an advertisement that required fan payment.

Enter the Matrix, a video game that became available on May 15, 2003, the same day as the film The Matrix Reloaded was released in theaters, was similarly tied into The Matrix trilogy. But it was not just a repetition of scenes from the first film, as many video game versions of films are, but rather offered a narrative extension. The Wachowski brothers wrote the script for the game, "using it to flesh out the movies' backstories and minor characters" (Bloom, 2003, p. 8). They filmed the game and movies simultaneously, "with the same cast and motion-capture tools" (p. 8). In promoting Enter the Matrix, marketers emphasized the fact that sequences unseen in the movie are played out in the video game. As such, Enter the Matrix was promoted as a bridge from the original Matrix film to its sequels (Bloom, 2003), appealing to fans who embraced the first film and building anticipation for the sequels.

The industry rhetoric surrounding the video game centered on "creator control." Matrix producer Joel Silver stated that "Hollywood's creative talents will increasingly want control over games based on their [films]" (Bloom, 2003, p. 8). He noted, "What is important to remember here is that entertainment is not just about storytelling anymore. . . . It's about building universes where people can express themselves. They want to dive in" (p. 8). And Infogames CEO Bruno Bonnell posited that 
Hollywood's "creatives will have to keep up": "There is going to be an obligation for directors to understand what's going on there, and they have to take part in it" (Bloom, 2003, p. 8).

But despite the public rhetoric, from the point of view of corporate owners, the "creative control" issue is secondary to promotional and revenue control. Hollywood studios have been paying close attention to the economic impact that licensed games have on the bottom line: Blockbuster video game releases can "generate $\$ 200$ million in revenues and lengthen a big franchise's fan base" (Bloom, 2003, p. 8). The connection between the video game industry and Hollywood is not a new one, though. As Wasko (1995) noted, in the early days of video games, cartoon and films characters were often licensed to game makers, and Warner Communications was even involved in the early video game market as it owned Atari. But the video game/Hollywood connection did not work as planned in the mid-1980s, due in part to the failure of the E.T. video game that cost $\$ 23$ million to produce. By the 1990s, however, Hollywood "rediscovered video games as an obvious element in their synergistic strategies" (p. 210). Wasko argued that video games are not "afterthoughts" for Hollywood majors "but are developed and produced simultaneously with a feature film" (p. 210). The majors may even "alter a film script to make more exciting games" as well as "shoot footage for video games at the same time the film is shot" (p. 210).

The game Enter the Matrix is certainly an exemplar of this. The distinctive feature of this synergetic strategy in Enter the Matrix is its emphasis on the intertextuality: A game is not merely a game version of the movie The Matrix but an integral part of a megatext, the Matrix trilogy or Matrix saga. An article by Goodale (2003) manifests the intention of constructing The Matrix as a textual event and a megatext rather than as a "routine" multimedia strategy:

The reason all the above is something more than just mondo Matrix-moneymaking is
that each of the above reveals a different part of the Matrix universe. The short films
streaming online reveal prequel information, and the video game features two smaller
characters from the second and third films, Ghost and Niobe, the latter played by Jada
Smith. Story lines in the game don't come directly from the movie. They explore the
known universe of all the "Matrix" characters. In fact, you can't even play the game as
the film's central character, Neo. (p. 20)

In this case, then, the video game does not just duplicate the plot of the movies but is part of a narrative expansion that focuses on motivations and back story of secondary characters. And the strategy seemingly worked, as Infogames Entertainment SA announced that it sold more than a million copies of the $\$ 49.99$ game a week after its release in the United States and Europe ("Matrix' Game Sales Pass 1 Million Total," 2003, p. 1).

Games may also continue the narrative even after the "original text" is completed. The Matrix Online, a multiplayer game, was touted as starting where the final film, 
Matrix Revolutions, ends. Within the game, players interact with characters from the films (Levine, 2005). Marketing costs for this game were $\$ 4$ million, and synergy abounded: Time Warner created two television advertisements intended to look like film trailers, America Online advertised the game "across its network as the first to incorporate AOL Instant Messenger technology into gameplay," DC Comics developed a bimonthly fanzine, HBO and Cinemax ran a promotion for the game for when The Matrix trilogy aired, and the Matrix 10-disc DVD set included a making-of-thegame disc (Hein, 2005, p. 1).

The Animatrix is a series of short animated films that provide additional back story to The Matrix, including the conflict between humans and machines that led to the Matrix's creation. Warner Brothers "positioned" the Animatrix as "a bridge between the game and the movie" (Lippman, 2003, p. B1), demonstrating again the flow from the original film and the sequels' marketing campaign to an additional media source. The DVD version is a compilation of nine animated shorts, four of which could be found on the Animatrix Web site (www.intothematrix.com). The marketing tactic was successful, for the Animatrix "became one of the top DVD premiere sellers of 2003, with consumers spending \$30.5 million to rent and buy it," and more than 4 million fans had downloaded at least one of the four animated shorts from the Internet, demonstrating that the campaign targeted fans effectively (Bowles, 2003a; Netherby, 2004, p. 1). Though The Animatrix is not essential to understanding the plots of the sequels, Silver noted, "it helps to understand the depth of the story" (Bowles, 2003a, p. D3). Thus, if one is a "devoted" fan of The Matrix and wants to uncover the intricacies of the film, he or she would need to purchase a copy of the DVD. The four shorts found on the Web site served as a teaser to entice fans into buying the compilation.

The Animatrix was also a marketing tool with a synergistic spin: A 9-min Animatrix episode, "The Final Flight of the Osiris," one of four episodes written by the Wachowski brothers, appeared in movie theaters with the Warner Brothers film Dreamcatcher (Snider, 2003). "The Final Flight of the Osiris" takes place after the original Matrix concludes and ends before The Matrix Reloaded commences. Thus, to understand what happened in the Matrix world beyond what fans saw in the box office films, purchasing the Animatrix DVD was a must. Furthermore, by showing the episode with another Warner Brothers film, the animated short served as an advertisement for the Animatrix DVD as well as for The Matrix sequels.

One may ask why Warner Brothers chose the animation form for the Animatrix. Most news coverage of the Animatrix emphasized that the Wachowski brothers are big Japanese animation (known as anime) fans and that The Matrix films were inspired by this popular form of Japanese animation (see, e.g., Solomon, 2003). In addition, there is a strong connection between the science fiction genre and anime. The "technological body" and "apocalyptic identity" have been main themes in Japanese anime (Napier, 2001; Solomon, 2003). However, this explanation tends to reduce the implication of The Animatrix to film directors' tastes or merely thematic 
similarities between sci-fi and anime. It ignores how the majors conceive the fan market and the advantage of animation for global appeal, in particular Asian markets and some portions of the European market.

Anime has recently become more popular in the English-speaking world, but it has been an enduring form and genre in Asia, in particular Japan, South Korea, and Taiwan (see Ahn, 2001). For example, in 2002, The Spiriting Away of Sen and Chihiro, directed by Hayao Miyazaki, broke box office records as the highest grossing film in Japan (Burr, 2002). Animation on television is a continuous presence from morning to late evening. And as Napier (2001) noted, "Japanese television studios produce around 50 animated series a year and a comparable number of Original Video Animations (OVA)" (p. 7). Anime audiences are also diverse, ranging from children to adults. Thus, The Animatrix, primarily directed by Japanese auteur anime directors, has dual markets: general audiences in Asia, on one hand, and anime and science fiction fans in the domestic market, on the other hand. Yet the filmography of directors ${ }^{2}$ of The Animatrix shows that the compilation targets the English-speaking world rather than Asian audiences, as a common feature of these directors is that their works had previously been introduced into the U.S. domestic market and have enjoyed increasing popularity among American anime fans.

In understanding Warner's strategies, we can see the emergence of a very profitable megatext, one that not only encourages the purchase of additional merchandise to demonstrate one's fandom but also promotes such additions as integral to the understanding of such an esoteric film as the original Matrix. One's fandom also includes the purchase of products associated with the film, products carefully woven into the scripts and whose advertisements mimicked the Matrix world.

\section{Corporate Tie-ins, Marketing, and Fandom}

In The Matrix, Neo asked Morpheus, "What is the Matrix?" Morpheus replies, "It's the world that has been pulled over your eyes to blind you from the truth." But for Warner Brothers, once the risk of producing the first Matrix proved a success, The Matrix trilogy became a cherished franchise. In the modern film industry, megafranchises include cross-promotional corporate partners. So despite the dark tone and not-so-hidden critique of consumer culture in the original film, the "A-list of tie-in partners" for The Matrix Reloaded included such companies as Samsung, Coca-Cola's Powerade, Heineken, and Cadillac (Hein, 2003, p. 3). Samsung became the global partner for Reloaded (including the subsequent DVD release), Revolutions, the Enter the Matrix video game, and the Animatrix DVD. In a textual analysis of The Matrix, Frentz and Rushing (2002) noted that "the hero within the technological myth will probably have to cut his or her ties to both in order to get a footing as an adult, as Neo does when he hangs up the phone, his link to the man-made mother" (p. 84). Although film critics focused on interpreting the meaning of "hanging up the phone," Samsung paid careful attention to the fact that the phone played 
a critical role in the movie and thus participated as one of the A-list tie-in partners. As Hein (2003) reported, "the electronics giant has the worldwide promotional rights for the films that cover wireless phone handsets and various consumer electronics categories including its audio/visual product lines, printers and monitors," and the company even produced a new, specially designed wireless phone that became a key product in the film (p. 3). Cadillac had extensive Reloaded product placement. General Motors's CTS and Escalade EXT vehicles were featured in a key chase sequence in Reloaded (Hein, 2003). In fact, GM has had a marketing/promotion partnership with Time Warner since 1999 (Graser \& Dunkley, 2003).

Powerade was not product-placed in either sequel, but it was a visible promotional partner by mixing Coca-Cola's "Very Real Power" message with The Matrix Reloaded. In a 1-minute ad shown in theaters, an Agent Smith look-alike, sitting at a desk next to a Powerade bottle, unemotionally speaks directly into the camera:

Greetings theater attendees. Right now, as you sit in your comfortable seats, viewing your filmed entertainment, perhaps enjoying something from the concession stand, consider this: The active human body can generate up to 12,000 BTUs of body heat. Pure, precious, life-giving energy. It is unfortunate your collective, puny little minds couldn't figure out a way to harness this energy. Put it to good use somehow. But that's besides the point. The point is, to keep generating all that energy, your body needs to be replenished. So, drink your Powerade. We have quotas to meet.

The ad then dissolves into the Matrix-like green digital code, with "The Matrix Has You 05.15 " overwritten on the screen. So in this way, the promotional partner becomes also part of the narrative, making Powerade a tongue-in-cheek Matrix co-conspirator.

Similarly, the Enter the Matrix video game also is a mix of the original movie's critique of consumer culture with definitive product placement. Although players see satirical "false consciousness" background billboards in the game with such sayings as "Watch T.V.," they also see billboards for Samsung phones. Powerade vending machines also appear in the game and can be interacted with by players (Whalen, 2006).

It is interesting that unlike Warner's Batman and the Harry Potter series, The Matrix Reloaded only had a "handful" of license deals, in part because the sequels, a two-set CD of the movie's songs, the video game, and the Animatrix DVD and downloads were released in such a short time frame (Lippman, 2003). Bruce Berman, president of Village Roadshow, stated, "The filmmakers did not want to alienate their fan base by selling out" (Lippman, 2003, p. B1). The fear was that Matrix fans "could be turned off by too much commercialization of the 'Matrix' mystique" (p. B1). However, even with the limited licensing and tie-in deals, The Matrix, a movie that seemingly admonishes consumer culture, indeed became commercialized as it sold Samsung phones, Cadillacs, beer, and a sports drink. As illustrated earlier, the corresponding advertising campaigns marketed not only the 
product but the movie as well, as the "movie refers back to the ads, which refer back to the film" (Ahrens, 2003, p. E1). And as Graser and Dunkley (2003) reported, Warner executives stated that "the sequels' filmmakers worked closely with the brands involved to come up with campaigns that work within the framework of the 'Matrix' world" (p. 84), an idea seemingly contradictory to the messages of the original Matrix. These tie-ins also help to cover the costs of production and marketing and minimize the out-of-pocket costs for Time Warner and production company Village Roadshow, which were expected to spend nearly $\$ 150$ million to market the sequels at the global level (Lippman, 2003).

\section{Conclusion}

As discussed, the most distinctive feature of promoting all commercial intertexts of The Matrix, such as two sequels of The Matrix, its DVD format, and the video game Enter the Matrix, is an emphasis on constructing the Matrix as a global textual event that attempts to move its fans via multiple revenue streams through the promise of an enriched story. As Meehan (1993) pointed out, "fans are bona fide consumers for a range of services and licensed products based on copyrights held by media conglomerates" (p. 392). Fans are not only profitable secondary markets for media companies but are also assured sales. As such, blockbuster sequels have preconstituted and presold audiences:

Fans buy habitually and ritually, discriminating among products on the basis of fans loyalty, not product quality. This ensures a steady demand for the repacking of copyrighted characters developed for one medium and then recycled through other media. For fans, the problem is to secure access to as much of the canon as possible; for copyright holders, the task is to expand that canon by proliferating as much merchandise as possible. (p. 392)

The Matrix trilogy demonstrates, however, that showing off one's fandom via hats or t-shirts is not enough. A new goal for transnational, transindustrial conglomerates is to ensure the flow of audiences from one medium to multiple platforms with storytelling characteristics. True Matrix fans are therefore constituted by their participation in the flow of fan activity that the companies involved create; the marketing strategy supports the notion that a "genuine" fan will purchase additional merchandise to deepen his or her understanding of the trilogy. The question for audience researchers becomes, How can actual audiences' activities and their interpretations be understood within such a narrativized textual event created by a massive media conglomerate? Although fans may have grappled with the meaning of The Matrix, producing their own texts via Web sites, for example, branding has become the ultimate strategy for cultural products: 
No matter how personally meaningful the process of textual interpretation, no matter how individually fulfilling the production of fan materials, the opportunities for interpretation and fan production spring from advertisers' need to regularize the consumption of brand name products in the international market. (Meehan, 1993, p. 394)

We would argue that these institutional structures and corporate goals, despite the potential for enhanced narrative, circumscribe media practitioner and audience creativity more than expand it. The Hollywood blockbuster and its subsequent connected texts provide materials for collective experiences and emotion, and it seemingly constructs a certain "generation" under the name of a cultural artifact, such as the Star Wars generation, post-Blade Runner generation, Akira generation, and The Matrix generation. However, inspired by a lesson from the original The Matrix, one could interpret the extended coordinated, connected fan materials as strategically manufactured visions not so much sustained by social awareness but by the driving force of consumption, profitability, synergy, and marketing. The critique of consumer culture found in the thought-provoking, esoteric inaugural Matrix was overwhelmed by its integration into a larger commodity intertextual flow that defined fandom as never complete and, in the case of the video game and crosspromotional advertising campaigns, placed real promotions for products in an environment that was originally critical of exactly this type of activity. As fans of the film watched the main character, Neo, unplug from the Matrix, Time Warner strategically encouraged those same fans to then plug into The Matrix brand and the commodity world this brand came to represent.

\section{Notes}

1. But one could also argue that the unprecedented simultaneous release of The Matrix Revolutions was driven by an attempt to protect the intellectual property rights of Hollywood's blockbusters from piracy. As Veronika Kwan-Rubinek of Warner's international distribution stated, “'It's a very provocative idea' . . 'Piracy has definitely been a big issue for us in determining the release strategy", (Graser \& Dunkley, 2003, p. 83). As such, the creation of this collective event that would allow fans of all ages across the globe to experience the final sequel simultaneously was actually a business plan that attempted not only to protect intellectual property but also created the hype for a global event that would financially benefit Time Warner, Village Roadshow, and the film's corporate tie-ins.

2. The anime "dream team" of animators and directors for the Animatrix includes Yoshiaki Kawajiri (Ninja Scroll and Vampire Hunter D), Shinchiro Watanabe (Cowboy Bebop), Koji Morimoto (Akira), Mahiro Maeda (Blue Submarine No. 6), Takeshi Koike (lead animator on several of director Kawajiri's films), Peter Chung (MTV's “Aeon Flux”), and Andy Jones (Final Fantasy: The Spirits Within).

\section{References}

Ahn, J. (2001, October). Animated subjects: On the circulation of Japanese animation as global cultural products. Paper presented at the Globalization and Popular Culture Workshop at the University of Manitoba, Canada. 
Ahrens, F. (2003, May 24). The movie: The Matrix: Reload . . The Washington Post, p. E1.

Alexander, K. L. (2000, April 20). DVD sales energize home video market. USA Today, p. B3.

Bird, E. (2003). The audience in everyday life: Living in a media world. New York: Routledge.

Bloom, D. (2003, February 16). Agents of change: Matrix meshes media. Variety, p. 8.

Bowles, S. (2003a, March 20). 'Animatrix' is perfect foil for 'Matrix' marketing blitz. USA Today, p. D3.

Bowles, S. (2003b, October 30). Revolution of Matrix. USA Today, p. D1.

Brooker, W. (2001). Living on Dawson's Creek: Teen viewers, cultural convergence, and television overflow. International Journal of Cultural Studies, 4(4), 456-472.

Burr, T. (2002, September 20). Animator's work is easy to love but hard to find outside of Japan. Boston Globe, p. C1.

Chetwynd, J. (1999, April 5). Mystery duo illuminates dark 'Matrix.' USA Today, p. D5.

Corliss, R. (1999, June 4). The big Wachowskis. The Guardian, p. T6.

Couldry, N. (2000). Inside culture: Re-imagining the method of cultural studies. London: Sage.

Eller, C. (2003a, April 16). Movie studios learn sharing burden can be risky business; Splitting ownership of films can lessen the pain of box-office flops, but it also means having to split enormous rewards. The Los Angeles Times, p. C1.

Eller, C. (2003b, May 13). 'Matrix' reloaded and set to shatter records. The Los Angeles Times, p. C1.

Entering the Matrix: Making the game. (2003). The Matrix reloaded [DVD]. Burbank, CA: Warner Home Video.

Fitzpatrick, E. (1999, October 23). No one can tell you what the Matrix is . . but Warner can tell you how to run the DVD. Billboard, p. 76.

Fitzpatrick, E. (2001, October 27). Picture this. Billboard, p. 75.

Frentz, S. T., \& Rushing, H. J. (2002). Mother isn't quite herself today: Myth and spectacle in The Matrix. Critical Studies in Media Communication, 19(1), 64-86.

Fuqua, J. V. (2003). 'What are those little girls made of?': The Powerpuff Girls and consumer culture. In C. A. Stabile \& M. Harrison (Eds.), Prime time animation: Television animation and American culture (pp. 205-219). New York: Routledge.

Goodale, G. (2003, February 14). It's a 'Matrix' kind of world; 'The Matrix' sequel doesn't come out until May, but the marketing machine has begun. Christian Science Monitor, p. 20.

Graser, M., \& Dunkley, C. (2003, January 20-26). The Matrix mantra. Variety, pp. 1, 83-84.

Harrison, E. (1999, April 6). It's time for a reality check. The Los Angeles Times, p. A1.

Hein, K. (2003, February 3). Matrix reloads. Brandweek, p. 3.

Hein, K. (2005, January 10). The Matrix saga continues in PC videogame format. Brandweek, p. 1.

Hesmondhalgh, D. (2002). The cultural industries. London: Sage.

Holson, L. M. (2003, November 5). Wrapping up a trilogy with a global assault. The New York Times, p. E1.

King, S. (1999, September 23). Digital media: Worlds open up on 'Matrix' DVD-ROM. The Los Angeles Times, p. 45.

Levine, R. (2005, April 25). The Matrix ever-loaded: Online game for the committed. The New York Times, p. C4.

Lippman, J. (2003, May 14). 'Matrix' overloaded?-The goal: Sell enough tie-ins to recoup costs without alienating fans. Wall Street Journal, p. B1.

'Matrix' game sales pass 1 million total. (2003, May 27). Wall Street Journal, p. 1.

McChesney, R. W. (2004). The problem of the media: U.S. communication politics in the 21 st century. New York: Monthly Review Press.

McCourt, J. (1999, April 18-24). Spring break crowds drive 'Matrix' revenue. Video Store, p. 14.

Meehan, E. R. (1991). 'Holy commodity fetish, Batman!': The political economy of commercial intertext. In R. E. Person \& W. Uricchio (Eds.), The many lives of the Batman: Critical approaches to a superhero and his media (pp. 47-65). New York: Routledge.

Meehan, E. R. (1993). Commodity audience, actual audience: The blind spot debate. In J. Wasko, V. Mosco, \& M. Pendakur (Eds.), Illuminating the blindspot: Essays honoring Dallas W. Smythe (pp. 378-400). Norwood, NJ: Ablex Publishing Corporation. 
Miller, T., Govil, N., McMurria, J., Maxwell, R., \& Wang, T. (2005). Global Hollywood 2. London: BFI Publishing.

Napier, J. S. (2001). Anime: From Akira to Princess Mononoke. New York: Palgrave.

Natale, R. (1999, April 16). Trying to tie up the Wachowski brothers. The Los Angeles Times, p. 14.

Netherby, J. (2004, March 1). For Universal DVDs, a summer full of synergy. Video Business, p. 1.

Nichols, P. M. (2001). More to satisfy 'Matrix' mania. The New York Times, p. E1.

Prange, S. (1999, August). 'Matrix' release planned for both rental and sellthrough. Video Store Magazine, pp. $1,37$.

Seiler, A. (2002, June 5). Same-year 'Matrix' sequels: Smooth move? USA Today, p. D7.

Snider, M. (2003, February 4). A multitude of 'Matrix' on the way; New films will be promoted in a variety of media. USA Today, p. D4.

Solomon, C. (2003, June 1). Inspired by the film they inspired; Anime influenced the 'Matrix' films. The Los Angeles Times, p. E24.

Sporich, B. (1999, October). Warner Home Video to push interactivity boundaries with online event for 'Matrix.' Video Store Magazine, p. 10.

Warner Bros. Pictures. (2003, September 29). Matrix Revolution zero hour global premiere. Retrieved October 3, 2003, from http://whatisthematrix.warnerbros.com/

Wasko, J. (1995). Hollywood in the information age. Austin: University of Texas Press.

Wasko, J. (2003). How Hollywood works. Beverly Hills, CA: Sage.

Whalen, Z. (2006, January 11). Product placement and virtual branding in video games. Gameology. Retrieved February 9, 2007, from http://www.gameology.org/node/121

Williams, R. (1974). Television: Technology and cultural form. New York: Schocken Books.

Jennifer M. Proffitt (PhD 2005, Pennsylvania State University) is an assistant professor in the College of Communication, Florida State University. Her research interests include political economy and media history and regulation.

At the time of her death in 2005, Djung Yune Tchoi was a $\mathrm{PhD}$ candidate in the College of Communications at Pennsylvania State University. Thanks to C. Michael Elavsky for assistance with later versions of this article.

Matthew P. McAllister ( $\mathrm{PhD}$ 1990, University of Illinois at Urbana-Champaign) is an Associate Professor in the Department of Film/Video \& Media Studies,Pennsylvania State University. His research interests include political economy and commercial culture. 